\title{
Mechanical Properties of Laminated Bamboo under Off-axis Compression
}

\author{
Dong Yang ${ }^{1 \mathrm{a}, 1 \mathrm{~b}}$, Haitao Li ${ }^{1 \mathrm{a}, 1 \mathrm{~b}^{*}}$, Zhenhua Xiong ${ }^{2}$, Leonel Mimendi ${ }^{1 \mathrm{a}, 1 \mathrm{~b}}$, Rodolfo Lorenzo ${ }^{3}$, Ileana \\ Corbi $^{4}$, Ottavia Corbi ${ }^{4}$, Chaokun Hong ${ }^{1 \mathrm{a}, 1 \mathrm{~b}}$ \\ ${ }^{\text {la }}$ College of Civil Engineering, Nanjing Forestry University, Nanjing 210037, China; ${ }^{1 b}$ Joint International Research \\ Laboratory of Bio-composite Building Materials and Structures, Nanjing Forestry University, Nanjing 210037, China \\ ${ }^{2}$ Ganzhou Sentai bamboo company LTD, Ganzhou 341001, China. \\ ${ }^{3}$ University College London, London WC1E 6BT, UK. \\ ${ }^{4}$ University of Naples Federico II, Via Claudio 21,80133 Naples, Italy. \\ *Corresponding author: Haitao LI, Professor, E-mail: 1haitao1982@126.com
}

Abstract: To investigate the compression performance of laminated bamboo, 210 laminated bamboo specimens were tested using seven different lamination angles. Six failure types were classified. All the specimens experienced elastic stage at the beginning of the loading process and then elastic-plastic stage. At the end of the elastic-plastic stage, specimens of $15^{\circ}, 30^{\circ}$ and $45^{\circ}$ immediately reached the ultimate bearing capacity, showing brittle failure, while other specimens entered a longer plastic stage before failure. The off-axis compression strength and the apparent elastic modulus both decreased with the increment of the angle. Two empirical formulas were proposed to predict the off-axis compression strength and apparent elastic modulus of laminated bamboo compared with several well-known failure criteria. The Poisson's ratio in $\mathrm{A} / \mathrm{C}$ planes increased with the increment of the angle while in $\mathrm{B} / \mathrm{D}$ planes, it increased and peaked at $30^{\circ}$ before decreasing. Based on Ramberg-Osgood relation, the compression and shear stress-strain curves were fitted.

Key words: A. Laminates; B. Mechanical properties; D. Mechanical testing 


\section{Introduction}

The constant increment of global temperature, mainly caused by the production of construction materials (47\% of carbon emissions) [1], has increased researchers' interest to use bamboo as an alternative and sustainable material [2-3]. Bamboo resources are rich around the world, with around 1200 species and a wide plantation area [4], from which $65 \%$ is in Asia, where the development prospect is the highest. The growth period of bamboo is relatively shorter than wood, usually bamboo could be harvested in 4-5 years. The mechanical performance of bamboo is comparable to that of wood [5-6], however, the energy consumption of bamboo production is far less than that of traditional building materials such as concrete, steel and cement, positioning bamboo as one of the greenest construction material [7].

Bamboo poles have been used as a traditional construction material for millennia, especially in Asian history. However, technical challenges of bamboo poles, such as geometric and mechanical variability [89], combined with the lack of methodologies to tackle these issues, restrict further development of bamboo poles. The natural decay resistance of bamboo was found to be less than 24 months [10]. Bamboo for outdoor use usually decays in about 4 years without treatment [11]. Also, during natural seasoning, bamboo poles tend to split along their grain due to uneven shrinkage [12]. Thus, the development of engineering bamboo has brought a range of structural products from which laminated bamboo is one of them [13-15].

Researchers have studied the mechanical properties of laminated bamboo [16-18]. By studying the elastic modulus and Poisson's ratio of laminated bamboo under different loading directions Takeuchi et al. [19] proved laminated bamboo could be treated as orthotropic material. Mahdavi et al. [20] found that the strength and rigidity of laminated bamboo is equivalent to that of wood and pointed out that laminated bamboo could be used as structural material. Sharma et al. [21] conducted bending, compression, tension 
and shear test on structural size laminated bamboo and compared the results with the properties of wood products such as Norway spruce, Glue laminated spruce and Thermally modified beech. Considering the influence of production technology, loading direction, specimen length and section size, Li et al. [22-24] carried out an experimental study on the compression performance of laminated bamboo and discussed the compression failure mechanism. Based on the experimental study and theoretical analysis, the stress-strain model and load displacement model of laminated bamboo were also proposed. Diaz et al. [25] studied the bending resistance of the laminated bamboo made from different parts of Guadua and results showed that the bending resistance of the laminated bamboo made from the bottom section of bamboo culm was higher compared to other sections.

Abundant achievements have been made in the study of mechanical properties of laminated bamboo but limited in the off-axis compression behavior. In a 3D structure, the loading direction can be acting in different directions, so it becomes important because laminated bamboo is not isotropic but orthotropic, the effects of those loads in different directions might change, shear failure could also happen. For better application of laminated bamboo as an alternative natural structural member, this work focused on the experimental test of 210 off-axis specimens under compression, where seven different lamination angles were examined. The failure types, compression strength, apparent shear modulus, shear strength, apparent elastic modulus and Poisson's ratio of laminated bamboo were studied and the corresponding empirical formulas were proposed. Based on the Ramberg-Osgood relation, the compression stress-strain curves and shear stress-strain curves of the laminated bamboo off-axis specimens were fitted.

\section{Specimens and test method}

\subsection{Raw material}


Specimens in this paper were all produced by Ganzhou Sentai bamboo Co., Ltd. Bamboo (Phyllostachys pubescens) around Yong'an, Fujian Province was used as raw material and the size of bamboo unit was $2005 \mathrm{~mm} \times 21 \mathrm{~mm} \times 7 \mathrm{~mm}$. With resorcinol as adhesive, laminated bamboo was made by hot pressing for about 15 minutes under the condition of main pressure of $9 \mathrm{MPa}$, side pressure of $6.5 \mathrm{MPa}$ and the temperature of $157^{\circ} \mathrm{C}$, as shown in Fig. 1 .

\subsection{Design of specimens}

According to fiber and lamination direction of the laminated bamboo, 7 groups of specimens with a certain offset angle $\theta$ between the fiber direction and the compression direction were made. The values of the angle $\theta$ were $0^{\circ}, 15^{\circ}, 30^{\circ}, 45^{\circ}, 60^{\circ}, 75^{\circ}, 90^{\circ}$, from which $0^{\circ}$ corresponds to the direction parallel to the grain of laminated bamboo and $90^{\circ}$ was perpendicular to grain. The naming rule of each group was "C + value of $\theta$ ". The size of specimens was $50 \mathrm{~mm} \times 50 \mathrm{~mm} \times 100 \mathrm{~mm}$, and for getting accurate and convincing test results, the number of specimens in each group was 30 . To identify the lateral faces of the specimens, the four sides of each specimen were named plane A, B, C, D in anticlockwise order, as shown in Fig.2a. The cross section of bamboo fiber could be seen in plane A and C, while the lamination angle could be seen in plane B and D.

\subsection{Test method}

The test was performed using a servo-controlled electro-hydraulic universal testing machine with a maximum load of $2000 \mathrm{kN}$. A TDS-530 data logger was used to collect the load, displacement and strain data simultaneously. The strain gauges were from Huangyan Linli Engineering Sensor Factory, Zhejiang, China. The size of the strain gauge sensitive grid was $10 \mathrm{~mm} \times 3 \mathrm{~mm}$, the resistance was $120 \Omega$ and the adhesive used for attachment was instantaneous drying glue 502 . 
In the initial stage of the experiment, if displacement control was used, the load increased rapidly, and the specimen entered the failure stage too quickly. Therefore, load control was used first to observe the development of micro cracks before the failure stage. When the specimen entered the failure stage, the displacement increased rapidly while load increased little, so it was switched to displacement control [26]. The whole loading duration was controlled in 6-8 minutes. The test scheme and the attachment method of strain gauges are shown in Fig.2b. The off-axis compression was achieved by intersecting fiber direction and loading direction with an angle of $\theta$. Two strain gauges were attached in both plane $\mathrm{A}$ and $\mathrm{C}$, while in plane $\mathrm{B}$ and $\mathrm{D}$, three strain gauges were attached. The strain gauges along and perpendicular to the loading direction were used for measuring $\varepsilon_{\mathrm{x}}$ and $\varepsilon_{\mathrm{y}}$ respectively, the other strain gauge which had certain degree of $45^{\circ}$ was used for measuring $\varepsilon_{45}$.

Considering that the deformation of the specimens was small before reaching the ultimate load, the area of a specimen was regarded as a constant during the test. The compression strength of laminated bamboo specimens was calculated by Eq.(1)

$$
f_{\theta}=\frac{P_{\mathrm{u}}}{A}
$$

where, $f_{\theta}$ is compression strength of specimens with the angle of $\theta ; P_{\mathrm{u}}$ is the ultimate load; $A$ is the cross-section area of the specimens.

The apparent elastic modulus of laminated bamboo can be obtained from Eq.(2):

$$
E_{\theta}=E_{\mathrm{x}}=\frac{\Delta \sigma_{\mathrm{x}}}{\Delta \varepsilon_{\mathrm{x}}}=\frac{\Delta P}{A \Delta \varepsilon_{\mathrm{x}}}
$$

where, $E_{\theta}$ is the apparent elasticity modulus of specimens with the angle of $\theta ; \Delta P$ is the load increment; $\Delta \varepsilon_{\mathrm{x}}$ is the strain increment at the elastic stage along to the loading direction.

Under the off-axis loading condition, the loading direction is at a certain angle with respect of the 
specimen's main axis direction, as shown in Fig.3. The stress and strain component corresponding to the loading direction of the specimens could be obtained by means of the stress and strain coordinate transformation, as Eq.(3) and Eq.(4):

$$
\begin{gathered}
{\left[\begin{array}{l}
\sigma_{1} \\
\sigma_{2} \\
\tau_{12}
\end{array}\right]=\left[\begin{array}{ccc}
m^{2} & n^{2} & 2 m n \\
n^{2} & m^{2} & -2 m n \\
-m n & m n & m^{2}-n^{2}
\end{array}\right]\left[\begin{array}{l}
\sigma_{\mathrm{x}} \\
\sigma_{\mathrm{y}} \\
\tau_{\mathrm{xy}}
\end{array}\right]} \\
{\left[\begin{array}{c}
\varepsilon_{1} \\
\varepsilon_{2} \\
\gamma_{12}
\end{array}\right]=\left[\begin{array}{ccc}
m^{2} & n^{2} & m n \\
n^{2} & m^{2} & -m n \\
-2 m n & 2 m n & m^{2}-n^{2}
\end{array}\right]\left[\begin{array}{c}
\varepsilon_{\mathrm{x}} \\
\varepsilon_{\mathrm{y}} \\
\gamma_{\mathrm{xy}}
\end{array}\right]}
\end{gathered}
$$

where, $m=\cos \theta ; n=\sin \theta ; \sigma_{1}, \sigma_{2}, \tau_{12}$ are the principal stress and shear stress corresponding to the material coordinate axis of specimens; $\sigma_{x}, \sigma_{y}, \tau_{x y}$ are the principal stress and shear stress corresponding to the loading coordinate; $\varepsilon_{1}, \varepsilon_{2}, \gamma_{12}$ are the strain and shear strain corresponding to the material coordinate axis; $\varepsilon_{\mathrm{x}}, \varepsilon_{\mathrm{y}}, \gamma_{\mathrm{xy}}$ are the strain and shear strain corresponding to loading coordinate.

According to the coordinate transformation equations, the apparent shear stress $\tau_{12}$, Eq.(5), and apparent shear strain $\gamma_{12}$, Eq.(6), corresponding to the material coordinate was obtained.

$$
\begin{gathered}
\tau_{12}=-\sigma_{\mathrm{x}} \sin \theta \cos \theta=-\frac{P}{A} \sin \theta \cos \theta \\
\gamma_{12}=2\left(\varepsilon_{\mathrm{y}}-\varepsilon_{\mathrm{x}}\right) \sin \theta \cos \theta+\gamma_{\mathrm{xy}}\left(\cos ^{2} \theta-\sin ^{2} \theta\right) \\
=2\left(\varepsilon_{\mathrm{y}}-\varepsilon_{\mathrm{x}}\right) \sin \theta \cos \theta+\left(\varepsilon_{45}-\varepsilon_{\mathrm{x}}-\varepsilon_{\mathrm{y}}\right)\left(\cos ^{2} \theta-\sin ^{2} \theta\right)
\end{gathered}
$$

where, $P$ is load; $\varepsilon_{\mathrm{x}}, \varepsilon_{\mathrm{y}}, \varepsilon_{45}$ are the strain in the axial direction, transverse direction and $45^{\circ}$ direction of specimens, respectively. Therefore, the in-plane apparent shear modulus of laminated bamboo can be obtained:

$$
G_{12}=\frac{\tau_{12}}{\gamma_{12}}
$$

In addition, when the ultimate load is $P_{\mathrm{u}}$, the apparent shear strength $S$ can be expressed as:

$$
S=-\frac{P_{\mathrm{u}}}{A} \sin \theta \cos \theta
$$


The Poisson's ratio was calculated by Eq.(9):

$$
\mu_{\mathrm{xy}}=\frac{\Delta \varepsilon_{\mathrm{y}}}{\Delta \varepsilon_{\mathrm{x}}}
$$

where, $\mu_{\mathrm{xy}}$ is Poisson's ratio; $\Delta \varepsilon_{\mathrm{x}}$ is the strain increment of the elastic stage along to the loading direction; $\Delta \varepsilon_{\mathrm{y}}$ is the strain increment of the elastic stage perpendicular to the loading direction.

\section{Failure phenomena analysis}

\subsection{Specimens with angle of $0^{\circ}$}

Failure type I was compression buckling failure along the grain, as shown in Fig.4a. During the loading process, specimens first appeared fine vertical cracks along the loading direction. With the increase of the load, these cracks gradually expanded and extended. The bamboo fibers on both sides of the crack began to buckle and deform until the compression buckling failure occurred and the ultimate bearing capacity was reached. 23 of the 30 specimens showed failure type I, accounting for the majority.

The remaining 7 specimens presented failure type II caused by the failure of adhesive layer, as shown in Fig.4b. Similar to failure type I, the crack started in-between lamination, however as the load increased the crack propagated from bottom to top of the sample, causing global failure. It is worth noting that type II was usually accompanied by local buckling failure, but the failure of adhesive layer was still dominant.

Failure type I and II happened because some layers started buckling, this produced a tension stress inbetween layers which was only carried by the glue. Samples failing in type II could have been produced with less glue or bonding problems.

\subsection{Specimens with angle of $15^{\circ}, 30^{\circ}$ and $45^{\circ}$}

Failure type III was an in-plane brittle shear failure, as shown in Fig.4c. From the beginning of the test, there was no sign of shear failure until the ultimate load was reached. Part of the load was borne between 
layers in the form of shear force, then the test specimens were suddenly sheared in the plane along the bamboo fiber direction with a loud "pop" sound. All specimens with angle of $15^{\circ}, 30^{\circ}$ and $45^{\circ}$ showed failure type III.

\subsection{Specimens with angle of $60^{\circ}, 75^{\circ}$ and $90^{\circ}$}

Failure type IV presented a "Y" shaped failure, as shown in Fig.4d. During the loading process, cracks in the loading direction first appeared in the middle of the A and C planes of the specimens. As the load increased, the cracks gradually expanded and extended from the middle to the end of the specimens, eventually forming a "Y" shape. 10,19 and 14 specimens showed Failure type IV for angles $60^{\circ}, 75^{\circ}$ and $90^{\circ}$ respectively.

Failure type V was local crushing failure, as shown in Fig.4e. Cracks along the loading direction appeared first on one side of the A and $\mathrm{C}$ planes of the specimens, and the cracks continued propagating with the increase of load. When the deformation of the specimen was too large, the B or D plane of the specimens suddenly bulged, at this time, the ultimate load was reached. 9 specimens showed failure type $\mathrm{V}$ for angles of $60^{\circ}$ and $75^{\circ}$ each, while 14 specimens with $90^{\circ}$ presented the same failure.

Failure type VI was shear failure transverse to grain, as shown in Fig.4(f). During the loading process, small cracks appeared first along the loading direction of the specimens, which continued to expand and eventually connected into a diagonal crack. At this point the ultimate load was reached. Different from failure type III which was along the direction of bamboo fiber, the crack extension of failure mode VI was perpendicular to the direction of bamboo fiber. 11 specimens with $60^{\circ}$ angle showed failure type VI, while 2 specimens with $75^{\circ}$ and $90^{\circ}$ angle presented the same failure each.

Failure type IV and VI happened because the bamboo fibers shifted perpendicular to the grain direction 
due to the compression. In failure type IV, the fibers shifted from two ends the sample and intersected in the sample's middle part, while the fibers shifted diagonally in failure type VI.

\section{Analysis of test results}

The statistical analysis of test results are shown in Table 1. SDV is the standard deviation, COV is the coefficient of variation, and $\mathrm{CHV}$ is the characteristic value (CHV $=$ mean value $-v \times \mathrm{SDV}, v$ is determined by the number of samples, in this case $v=1.67$ [27]). Except Poisson's ratio, the coefficient of variation of the test results is lower than $12 \%$, for compression strength parallel and perpendicular to grain, the COV is $4.14 \%$ and $8.7 \%$ respectively, indicating that the test results are relatively stable.

The comparison of laminated bamboo to wood and wood-based products is shown in Table 2. It is obvious that the compression strength of laminated bamboo parallel and perpendicular to grain is higher than other wood-based products, the elastic modulus is in the same level of other wood-based products, thus bamboo can be an alternative natural structural member.

\subsection{Load-displacement curves}

The load-displacement curves of 7 groups of specimens with different angles are summarized in Fig.5. At the beginning of the loading process, all the specimens went through elastic stage, in which the stiffness of each group of specimens was relatively stable, and then entered elastic-plastic stage with a gradual reduction of stiffness. Specimens with angle of $15^{\circ}, 30^{\circ}$ and $45^{\circ}$ reached the ultimate bearing capacity immediately after the end of the elastic-plastic stage (Fig.5b, c, d), showing brittle failure. However, specimens with angle of $0^{\circ}, 60^{\circ}, 75^{\circ}$ and $90^{\circ}$ entered a long plastic stage after the elastic-plastic (Fig.5a, e, f, g), with a long yield platform, and then entered the failure stage.

\subsection{Analysis of compression strength}


Laminated bamboo is regarded as orthotropic material and the off-axis compression test of laminated bamboo is simplified as the plane stress problem of composite material. Commonly used strength criteria were employed to predict the compression strength of laminated bamboo off-axis specimens and the applicability of these criteria to laminated bamboo was examined.

Hill [34] introduced various anisotropic coefficients and ignored Bauschinger effect, and proposed Hill's failure criterion based on von Mises's criterion [35] to deal with the strength problem of anisotropic materials. The expression under plane stress is as Eq.(10):

$$
\left(\frac{\sigma_{1}}{f_{1}}\right)^{2}+\left(\frac{\sigma_{2}}{f_{2}}\right)^{2}-\left(\frac{1}{f_{1}^{2}}+\frac{1}{f_{2}^{2}}\right) \cdot \sigma_{1} \cdot \sigma_{2}+\left(\frac{\tau_{12}}{S}\right)^{2}=1
$$

where, $f_{1}, f_{2}$ are the compression strength of the material parallel and perpendicular to grain, respectively, in this paper, they correspond to the strength of specimens with angle of $0^{\circ}$ and $90^{\circ}$.

Azzi and Tsai [36] regarded unidirectional fiber composite as transversely isotropic and applied Hill's criterion on it. Considering the interaction of the principal stresses in three directions and the corresponding strength, they proposed Tsai-Hill's criterion, the expression under plane stress is as Eq.(11):

$$
\left(\frac{\sigma_{1}}{f_{1}}\right)^{2}+\left(\frac{\sigma_{2}}{f_{2}}\right)^{2}-\frac{1}{f_{1}^{2}} \cdot \sigma_{1} \cdot \sigma_{2}+\left(\frac{\tau_{12}}{S}\right)^{2}=1
$$

Norris [37] put forward the strength criterion of orthotropic material which is specially used for wood. In the plane stress state, Eq.(12) could be used to predict failure of material if any one of them is satisfied.

$$
\left(\frac{\sigma_{1}}{f_{1}}\right)^{2}+\left(\frac{\sigma_{2}}{f_{2}}\right)^{2}-\frac{1}{f_{1} f_{2}} \cdot \sigma_{1} \cdot \sigma_{2}+\left(\frac{\tau_{12}}{S}\right)^{2}=1 ;\left(\frac{\sigma_{1}}{f_{1}}\right)^{2}=1 ;\left(\frac{\sigma_{2}}{f_{2}}\right)^{2}=1
$$

Alternative and simpler equations, Line criterion, Eq.(13), and Quadratic criterion, Eq.(14), have been developed for their use in wood materials. The applicability of these formulas on laminated bamboo will be studied in this work 


$$
\begin{gathered}
\frac{\sigma_{1}}{f_{1}}+\frac{\sigma_{2}}{f_{2}}+\frac{\tau_{12}}{S}=1 \\
\left(\frac{\sigma_{1}}{f_{1}}\right)^{2}+\left(\frac{\sigma_{2}}{f_{2}}\right)^{2}+\left(\frac{\tau_{12}}{S}\right)^{2}=1
\end{gathered}
$$

Introducing Eq.(10) to Eq.(14) into Eq.(3), the expressions of off-axis compression strength $f_{\theta}$ under each strength criterion could be obtained. Eq.(15) to Eq.(19) correspond to Hill's criterion, Tsai-Hill's criterion, Norris’s criterion, Line criterion and Quadratic criterion respectively.

$$
\begin{gathered}
f_{\theta}^{2}=1 /\left(\frac{\cos ^{4} \theta}{f_{1}^{2}}+\frac{\sin ^{4} \theta}{f_{2}^{2}}-\frac{\sin ^{2} \theta \cos ^{2} \theta}{f_{1}^{2}}-\frac{\sin ^{2} \theta \cos ^{2} \theta}{f_{2}^{2}}+\frac{\sin ^{2} \theta \cos ^{2} \theta}{S^{2}}\right) \\
f_{\theta}^{2}=1 /\left(\frac{\cos ^{4} \theta}{f_{1}^{2}}+\frac{\sin ^{4} \theta}{f_{2}^{2}}-\frac{\sin ^{2} \theta \cos ^{2} \theta}{f_{1}^{2}}+\frac{\sin ^{2} \theta \cos ^{2} \theta}{S^{2}}\right) \\
f_{\theta}^{2}=1 /\left(\frac{\cos ^{4} \theta}{f_{1}^{2}}+\frac{\sin ^{4} \theta}{f_{2}^{2}}-\frac{\sin ^{2} \theta \cos ^{2} \theta}{f_{1} f_{2}}+\frac{\sin ^{2} \theta \cos ^{2} \theta}{S^{2}}\right) \\
f_{\theta}=1 /\left(\frac{\cos ^{2} \theta}{f_{1}}+\frac{\sin ^{2} \theta}{f_{2}}+\frac{\sin \theta \cos \theta}{S}\right) \\
f_{\theta}^{2}=1 /\left(\frac{\cos ^{4} \theta}{f_{1}^{2}}+\frac{\sin ^{4} \theta}{f_{2}^{2}}+\frac{\sin ^{2} \theta \cos \theta}{S^{2}}\right)
\end{gathered}
$$

If the influence of shearing is ignored, the strength expression calculated by the Linear criterion turns into Hankinson formula [38], which was an empirical formula proposed by Hankinson based on off-axis compression test of wood:

$$
f_{\theta}=\frac{f_{1} f_{2}}{f_{1} \sin ^{2} \theta+f_{2} \cos ^{2} \theta}
$$

In addition, some scholars [39] extended Hankinson formula to Eq.(21). Where $n$ is a constant.

$$
f_{\theta}=\frac{f_{1} f_{2}}{f_{1} \sin ^{n} \theta+f_{2} \cos ^{n} \theta}
$$

According to experimental results, the compression strength of laminated bamboo off-axis specimens decreased with the increase of the angle $\theta$. The compression strength decreased greatly from $0^{\circ}$ to $45^{\circ}$, 
and the compression strength of the specimens with angle from $60^{\circ}$ to $90^{\circ}$ didn't drop as much as from that of $0^{\circ}$ to $45^{\circ}$. Therefore, an empirical formula, Eq.(22), based on the exponential function and the sine function was proposed to fit the compression strength of off-axis laminated bamboo specimens.

$$
f_{\theta}=f_{0} e^{\alpha \sin \theta}
$$

Where, $f_{0}$ is the compression strength of the specimens with $0^{\circ} ; \alpha$ is a constant.

Fig.6 shows the compression strength of specimens in each group and the fitting results of each criterion and formula. It can be seen that the empirical formula proposed in this paper and the Hankinson formula when $n=1.5$ are more accurate for predicting the off-axis compression strength of laminated bamboo. When $n=2$, Hankinson formula predicts higher compression strength when $\theta$ is less than $60^{\circ}$. Compression strength obtained by Hankinson formula and Hill's criterion is higher than test result when $\theta \leq 30^{\circ}$. Results calculated by Norris criterion, Tsai-Hill's criterion and Quadratic criterion are similar, but the predicted results are smaller than test results when $\theta \geq 30^{\circ}$. And the Line criterion predicts small compression strength overall.

The empirical formula proposed in this paper was fitted, and the value of $\alpha$ is $-1.286, \mathrm{R}^{2}=0.973$.

\subsection{Poisson's ratio}

Poisson's ratio of each specimens in different planes is shown in Fig.7a and Fig.7b. It could be seen that in plane A and C, Poisson's ratio increased with the increment of $\theta$. While in plane $\mathrm{B}$ and $\mathrm{D}$, when $\theta \leq 30^{\circ}$, the Poisson's ratio increased gradually, however, when $\theta>30^{\circ}$, the Poisson's ratio decreased, which is similar with the test results of Pindera and Herakovich [40]. The Poisson's ratio of A/C planes and B/D planes corresponding to $\theta$ can be approximately calculated by Eq.(23-1) with $\mathrm{R}^{2}=0.451$ and, Eq.(23-2) with $\mathrm{R}^{2}=0.846$. respectively. 


$$
\begin{aligned}
& \mu_{\mathrm{xy}}^{\mathrm{AC}}=0.36771+0.00321 \theta-9.07496 \theta^{2}-2.95062 \theta^{3} \\
& \mu_{\mathrm{xy}}^{\mathrm{BD}}=0.30351+0.00731 \theta-2.51423 \theta^{2}+1.55186 \theta^{3}
\end{aligned}
$$

\subsection{Apparent shear modulus}

The in-plane apparent shear modulus and apparent shear strength are shown in Fig.8. It can be seen that the in-plane apparent shear modulus obtained by Eq.(7) was relatively average for all groups. The mean apparent shear modulus of all specimens was $1164.8 \mathrm{MPa}$, and the coefficient of variation was $11.44 \%$. For shear strength, the failure mode of $60^{\circ}$ and $75^{\circ}$ specimens were not in-plane shear failure, so Eq.(8) is not applicable to these specimens, only the results of $15^{\circ}, 30^{\circ}$ and $45^{\circ}$ specimens are plotted. It can be seen that the shear strength measured from the $30^{\circ}$ specimens was higher, and the shear strength calculated from the $15^{\circ}$ specimens is smaller. The average shear strength of all specimens was $14.7 \mathrm{MPa}$, and the coefficient of variation was $13.24 \%$.

\subsection{Apparent elastic modulus}

Bodig and Jayne [39] proposed an empirical formula of $E_{\theta}$ according to Hankinson formula:

$$
E_{\theta}=\frac{E_{1} E_{2}}{E_{1} \sin ^{2} \theta+E_{2} \cos ^{2} \theta}
$$

Where, $E_{1}, E_{2}$ are the elastic modulus parallel and perpendicular to grain respectively, corresponding to specimens at $0^{\circ}$ and $90^{\circ}$ in this paper.

Jones [41] believed that the elastic modulus of off-axis specimen should be related to the shear modulus, the elastic modulus parallel and perpendicular to grain and the Poisson's ratio, and the expression of $E_{\theta}$ was deduced by the coordinate transformation of the orthotropic elasticity relations:

$$
\frac{1}{E_{\theta}}=\frac{\cos ^{4} \theta}{E_{1}}+\frac{\sin ^{4} \theta}{E_{2}}-\frac{2 \mu_{12} \cos ^{2} \theta \sin ^{2} \theta}{E_{1}}+\frac{\cos ^{2} \theta \sin ^{2} \theta}{G_{12}}
$$

Liu and Ross [42] presented an equivalent formula: 


$$
E_{\theta}=\frac{E_{1} E_{2}}{E_{2} \cos ^{2} \theta\left(\cos ^{2} \theta+a \sin ^{2} \theta\right)+E_{1} \sin ^{4} \theta}
$$

where,

$$
a=\frac{E_{1}}{G_{12}}-2 \mu_{12}
$$

Saliklis and Falk [43] considered that the above equations involved too many parameters, so Eq.(28) was put forward without Poisson's ratio, and the correctness of the formula was verified according to the results of off-axis tension test of three kinds of wood.

$$
\frac{1}{E_{\theta}}=\frac{\cos ^{4} \theta}{E_{1}}+\frac{\sin ^{4} \theta}{E_{2}}+\frac{\cos ^{2} \theta \sin ^{2} \theta}{\left(\lambda^{2 \lambda}\right) G_{12}}
$$

where $\lambda=E_{2} / E_{1}$.

According to test results, the elastic modulus of specimens decreased with the increase of the angle $\theta$.

The reduced amplitude of the elastic modulus was larger when $0^{\circ} \leq \theta<45^{\circ}$, and the elastic modulus when $45^{\circ}<\theta \leq 90^{\circ}$ tended to be gentle. Eq.(22) was rewritten as Eq.(29), and the compression elastic modulus of the off-axis specimens was fitted.

$$
E_{\theta}=E_{0} e^{\beta \sin \theta}
$$

Where, $E_{0}$ is the elastic modulus of the angle $0^{\circ} ; \beta$ is a constant.

Fig.9 shows the elastic modulus of the specimens and the fitting results of each formula. It can be seen that the formula proposed in this paper, Hankinson formula and Jones formula are relatively consistent with the test results, but Hankinson formula and Jones formula are slightly higher for the prediction of the elastic modulus of specimens of $15^{\circ}$. Saliklis and Falk's formula is not good for the prediction of elastic modulus, which may be because it was based on the off-axis tension test.

The proposed empirical equation was fitted and the value of $\beta$ value was $-1.625, \mathrm{R}^{2}=0.982$.

\subsection{Stress-strain curves}


The stress-strain curves of specimens of each group are shown in Fig.10a-g. The strain was collected by strain gauges, however, the strain gauges were already damaged due to the failure and deformation of specimens, so there is no falling section in stress-strain curves. It can be seen that except the specimens with $0^{\circ}$, the stress-strain curves of the other groups of specimens only experienced the elastic and elasticplastic stages, and there was no obvious yield point. After the end of the elastic-plastic stage, the $0^{\circ}$ specimens also experienced a long plastic stage. In addition, the ultimate strain of $0^{\circ}$ specimen was larger than that of other groups. The ultimate strain of other groups increased gradually from $0^{\circ}$ to $90^{\circ}$ specimens, but it was still far less than that of $0^{\circ}$ specimens.

Some researchers have suggested strain-stress models for bamboo-based composites, which include twosegment model and three-segment model [22]. These models use piecewise functions to fit the shape of the stress-strain relation, in further calculation, it is inconvenient to calculate each function separately. Also, it is difficult to determine each junction point accurately for there being no significant segment point on the stress-strain curve [3]. Ramberg-Osgood relation [44] is often used to describe the stress-strain relation without yield point and the expression is simple. Its original expression is:

$$
\varepsilon=\varepsilon_{\mathrm{e}}+\varepsilon_{\mathrm{p}}=\frac{\sigma}{E}+K\left(\frac{\sigma}{E}\right)^{t}
$$

where, $\varepsilon_{e}$ dominates elastic stage, $\varepsilon_{p}$ dominates plastic stage; $\sigma$ is stress; $E$ is Young's modulus; $K$ and $t$ are constants. The Young's modulus $E$ could be replaced by any corresponding stress and strain in the elastic stage of the stress-strain curve as a reference point, then Eq.(31) can be obtained:

$$
\frac{\varepsilon}{\varepsilon_{\mathrm{r}}}=\frac{\sigma}{\sigma_{\mathrm{r}}}+K \varepsilon_{\mathrm{r}}^{t-1}\left(\frac{\sigma}{\sigma_{\mathrm{r}}}\right)^{t}
$$

Taking $s=K \varepsilon_{r}^{t-1}$, Eq.(32) can be obtained, which can be used to describe the elastic and elastic-plastic stages of the stress-strain curve of the laminated bamboo under off-axis compression. 


$$
\frac{\varepsilon}{\varepsilon_{\mathrm{r}}}=\frac{\sigma}{\sigma_{\mathrm{r}}}+s\left(\frac{\sigma}{\sigma_{\mathrm{r}}}\right)^{t}
$$

For consideration of the plastic stage, the total stress-strain relationship can be expressed as Eq.(33):

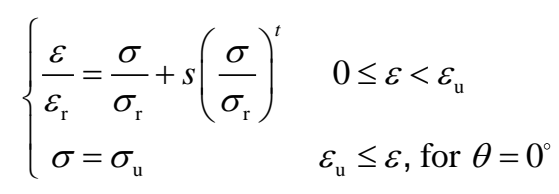

Where, $\sigma_{\mathrm{u}}$ is ultimate stress; $\varepsilon_{\mathrm{u}}$ is the strain corresponding to ultimate stress.

The stress-strain curves calculated according to Eq.(33) are compared with the test results as shown in Fig.10h. The numbers of specimens are C0-1, C15-1, C30-1, C45-1, C60-1, C75-1, C90-1. The stress-strain curves obtained by Ramberg-Osgood relation are quite consistent with the test results.

\subsection{Shear stress-strain curves}

The shear stress-strain curves obtained according to Eq.(20) and Eq.(21) are shown in Fig.11a-c. Since the failure types of $60^{\circ}$ and $75^{\circ}$ specimens are not shear failure, the shear stress calculated according to Eq.(8) in the later stage of the experiment was not correct, so these two groups of specimens are not plotted. It can be seen that the shear stress-shear strain curves of specimens from $15^{\circ}$ to $45^{\circ}$ all experienced elastic stage and elastic-plastic stage.

Similar with the stress-strain curves, the shear stress-strain curves can also be described by RambergOsgood relation. Rewrite Eq.(32) and Eq.(34) can be obtained:

$$
\frac{\gamma}{\gamma_{\mathrm{r}}}=\frac{\tau}{\tau_{\mathrm{r}}}+s\left(\frac{\tau}{\tau_{\mathrm{r}}}\right)^{t}
$$

where, $\tau_{\mathrm{r}}$ and $\gamma_{\mathrm{r}}$ correspond to the reference point of shear stress and shear strain.

According to Eq.(34), the shear stress-strain curves were fitted and compared with the test results, as shown in Fig.11d. The specimen numbers are C15-2, C30-2 and C45-2 respectively. It can be seen that the 
predicted results are quite consistent with the test results.

\section{Conclusions}

1. The failure phenomena of laminated bamboo off-axis compression test can be divided into three major types which include six minor types according to the off-axis angle. $0^{\circ}$ specimens showed typical parallelto-grain failure mode; $15^{\circ}, 30^{\circ}$ and $45^{\circ}$ specimens showed shear failure mode; and $60^{\circ}, 75^{\circ}$ and $90^{\circ}$ specimens showed typical perpendicular-to-grain failure mode.

2. At the beginning of the loading process, the off-axis laminated bamboo compression specimens all experienced elastic stage, in which the stiffness of each group of specimens was relatively stable, and then entered the elastic-plastic stage with a gradually reduction of stiffness. At the end of the elastic-plastic stage, the specimens of $15^{\circ}, 30^{\circ}$ and $45^{\circ}$ immediately reached the ultimate bearing capacity and entered the failure stage, showing brittle failure. However, $0^{\circ}, 60^{\circ}, 75^{\circ}$ and $90^{\circ}$ specimens entered a plastic stage with a long yield platform before failure.

3. An empirical formula based on exponential and sine function is proposed to predict the off-axis compression strength of laminated bamboo, which is also compared with the predicted results of several commonly used failure criteria. It is found that the empirical formula proposed in this paper and Hankinson formula when $n=1.5$ are more accurate for predicting the off-axis compression strength of laminated bamboo.

4. The Poisson's ratio of laminated bamboo in off-axis plane increased first and then decreased with the change of the off-axis angle and reached the maximum when the off-axis angle is $30^{\circ}$. The average Poisson's ratio parallel to grain $\left(0^{\circ}\right)$ and perpendicular to grain $\left(90^{\circ}\right)$ are 0.31 and 0.06 respectively.

5. The apparent shear modulus and shear strength of laminated bamboo were calculated by coordinate 
transformation of the orthotropic elasticity relations. The values of in-plane apparent shear modulus of laminated bamboo obtained by off-axis compression test were relatively average. Because the failure type of $60^{\circ}, 75^{\circ}$ and $90^{\circ}$ specimens are non-shear failure, the shear strength of these specimens cannot be calculated properly. The shear strength was therefore calculated from $15^{\circ}, 30^{\circ}$ and $45^{\circ}$ specimens, being $30^{\circ}$ the specimens showing the average highest value.

6. The apparent elastic modulus of off-axis laminated bamboo specimens decreased with the increase of the off-axis angle, with a decrease amplitude that lessened for every increment of angle. The proposed empirical formula based on exponential and sine function, Hankinson formula and Jones formula were more accurate for the prediction of apparent elastic modulus.

7. Based on Ramberg-Osgood relation, the stress-strain relationship and shear stress-strain relationship of off-axis laminated bamboo specimens were fitted and quite consistent with the test results.

Funding: This work was supported by the National Natural Science Foundation of China (No. 51878354 \& 51308301); the Natural Science Foundation of Jiangsu Province (No. BK20181402 \& BK20130978); Postgraduate Research \&Practice Innovation Program of Jiangsu Province; Six talent peak high-level projects of Jiang-su Province (No. JZ-029); and a Project Funded by the Priority Academic Program Development of Jiangsu Higher Education Institutions. Any research results expressed in this paper are those of the writer(s) and do not necessarily reflect the views of the foundations.

Acknowledgment: The writers gratefully acknowledge Han Zhang, Ke Zhou, Zhen Wang, Hang Li, Xiaoyan Zheng, Shaoyun Zhu, Liqing Liu, Dunben Sun, Jing Cao, Yanjun Liu and others from the Nanjing Forestry University for helping with the tests.

The authors declare that they have no conflicts of interest to this work. 


\section{References}

[1] Allwood J M, Cullen J M, Carruth M A, et al. Sustainable materials: with both eyes open. Cambridge, UK: UIT Cambridge Limited, 2012.

[2] Kaminski S, Lawrence A, Trujillo D. Structural use of bamboo: Part 1: Introduction to bamboo. Struct Eng 2016;94(8):40-43.

[3] Qiu Z, Fan H. Nonlinear modeling of bamboo fiber reinforced composite materials. Compo Struct 2020;238:111976.

[4] Khalil H A, Bhat I U H, Jawaid M, Zaidon A, Hermawan D, Hadi Y S. Bamboo fibre reinforced biocomposites: A review. Mater Design 2012;42:353-368.

[5] Chung K, Yu W. Mechanical properties of structural bamboo for bamboo scaffoldings. Eng Struct 2002;24:429-42.

[6] Awalluddin D, Mohd Ariffin M, Osman M, Hussin M, Seung Lee H, Abdul Shukor Lim N. Mechanical properties of different bamboo species. In: MATEC Web of Conferences. EDP Sciences, 2017. Vol.138, p.01024.

[7] Ghavami K. Modern bamboo structures. CRC Press, 2008. p.17-34.

[8] Lorenzo R, Mimendi L, Godina M, Li H T. Digital analysis of the geometric variability of Guadua, Moso and Oldhamii bamboo. Constr Build Mater, 2020;236:117535.

[9] Lorenzo R, Godina M, Mimendi L, Li H T. Determination of the physical and mechanical properties of moso, guadua and oldhamii bamboo assisted by robotic fabrication. J Wood Sci 2020;66(1):1-11.

[10] Chen L F, Su H T, Liu L, et al. Experimental study on corrosion resistance and natural corrosion resistance of 11 kinds of bamboo. Guangdong For Sci Technol 2007,23(1):34-36. 
[11] Sun F L, Prosper N K, Wu H P, et al. A review on the development of wood and bamboo preservation. J For Eng 2017,2:1-8.

[12] Wu K T. The effect of high-temperature drying on the antisplitting properties of makino bamboo culm (Phyllostachys makinoi Hay.). Wood Sci Technol 1992,26(4):271-277.

[13] Mahdavi M, Clouston P L, Arwade S R. A low-technology approach toward fabrication of laminated bamboo lumber. Constr Build Mater 2012;29:257-262.

[14] Verma C S, Chariar V M. Stiffness and strength analysis of four layered laminate bamboo composite at macroscopic scale. Compos Part B-Eng 2013;45(1):369-376.

[15] Sharma B, Gatóo A, Ramage M H. Effect of processing methods on the mechanical properties of engineered bamboo. Constr Build Mater 2015;83:95-101.

[16] Verma C S, Chariar V M. Development of layered laminate bamboo composite and their mechanical properties. Compos Part B-Eng 2012;43(3):1063-1069.

[17] Sinha A, Way D, Mlasko S. Structural performance of glued laminated bamboo beams. J Struct Eng 2014;140(1):04013021.

[18] Khoshbakht N, Clouston P L, Arwade S R, Schreyer A C. Computational modeling of laminated veneer bamboo dowel connections. J Mater Civil Eng 2018;30(2):04017285.

[19] Takeuchi C P, Estrada M, Linero D L. The Elastic Modulus and Poisson's Ratio of Laminated Bamboo Guadua angustifolia. In: Key Engineering Materials. Trans Tech Publications Ltd, 2016. Vol.668, p.126-133.

[20] Mahdavi M, Clouston P L, Arwade S R. Development of laminated bamboo lumber: review of processing, performance, and economical considerations. J Mater Civil Eng, 2011;23(7):1036-1042. 
[21] Sharma B, Bauer H, Schickhofer G, Ramage M H. Mechanical characterisation of structural laminated bamboo. P I Civil Eng-Str B 2017;170(4):250-264.

[22] Li H T, Zhang Q S, Huang D S, Deeks A J. Compressive performance of laminated bamboo. Compos Part B-Eng 2013;54:319-328.

[23] Li H T, Su J W, Zhang Q S, Chen G. Experimental study on mechanical performance of side pressure laminated bamboo beam. J Build Struct 2015;36(3):121-126.

[24] Li H T, Su J W, Zhang Q S, Deeks A J, Hui D. Mechanical performance of laminated bamboo column under axial compression. Compos Part B-Eng 2015;79:374-382.

[25] Díaz G A, Cruz R A, Chávez A M. Optimization of the bamboo guadua angustifolia kunth in the elaboration of glued laminated elements for constructive use. In: Journal of Physics: Conference Series. IOP Publishing, 2013. Vol.466, No.1, p.012032.

[26] Wei Y, Wu Y F. Compression behavior of concrete columns confined by high strength steel wire. Constr Build Mater 2014,54:443-453.

[27] EN 1990 C E N. Eurocode: Basis of structural design. United Kingdom: British Standards Institute, 2002.

[28] De Lorenzis L, Scialpi V, La Tegola A. Analytical and experimental study on bonded-in CFRP bars in glulam timber. Compos Part B-Eng 2005,36(4):279-289.

[29] Widmann R, Fernandez-Cabo J L, Steiger R. Mechanical properties of thermally modified beech timber for structural purposes. Eur J Wood Wood Prod 2012,70(6):775-784.

[30] Zhou J, Feng X, Zhou X. Experimental research on mechanical properties of larch glulam. J Central South University For Technol 2016,36(8):125-129. 
[31] Gasparri E, Lam F, Liu Y. Compression perpendicular to grain behavior for the design of a prefabricated CLT façade horizontal joint. In: 4th World Conference on Timber Engineering, 2016. p.1-11.

[32] Kretschmann D. Mechanical properties of wood. In: Wood handbook: wood as an engineering material: Chapter 5. Centennial ed. General technical report FPL; GTR-190. Madison, WI: US Dept. of Agriculture, Forest Service, Forest Products Laboratory, 2010. p.5.1-5.46.

[33] Kim Y J, Harries K A. Modeling of timber beams strengthened with various CFRP composites. Eng Struct 2010,32(10):3225-3234.

[34] Hill R. A theory of the yielding and plastic flow of anisotropic metals. Proceedings of the Royal Society of London. Series A. Mathematical and Physical Sciences, 1948;193(1033):281-297.

[35] Mises R. Mechanik der festen Körper im plastisch-deformablen Zustand. Nachrichten von der Gesellschaft der Wissenschaften zu Göttingen, Mathematisch-Physikalische Klasse, 1913;1913:582592.

[36] Azzi V D, Tsai S W. Anisotropic strength of composites. Exp Mec, 1965;5(9):283-288.

[37] Norris C. Strength of orthotropic materials subjected to combined stresses. 1962.

[38] Hankinson R L. Investigation of crushing strength of spruce at varying angles of grain. Air service information circular 1921;3(259):130.

[39] Bodig J, Jayne B A. Mechanics of wood and wood composites. New York: Van Nostrand Reinhold, 1982.

[40] Pindera M J, Herakovich C T. Shear characterization of unidirectional composites with the off-axis tension test. Exp Mec 1986;26(1):103-112. 
[41] Jones R M. Mechanics of composite materials. CRC press, 1998.

[42] Liu J Y, Ross R J. Wood mechanical property variation with grain slope. In: Proceedings of the 12th Engineering Mechanics Conference. La Jolla, California. 1998.

[43] Saliklis E P, Falk R H. Correlating off-axis tension tests to shear modulus of wood-based panels. J Struct Eng 2000;126(5):621-625.

[44] Ramberg W, Osgood W R. Description of stress-strain curves by three parameters. NACA Technical Note 902, National Bureau of Standards, Washington DC, 1943. 


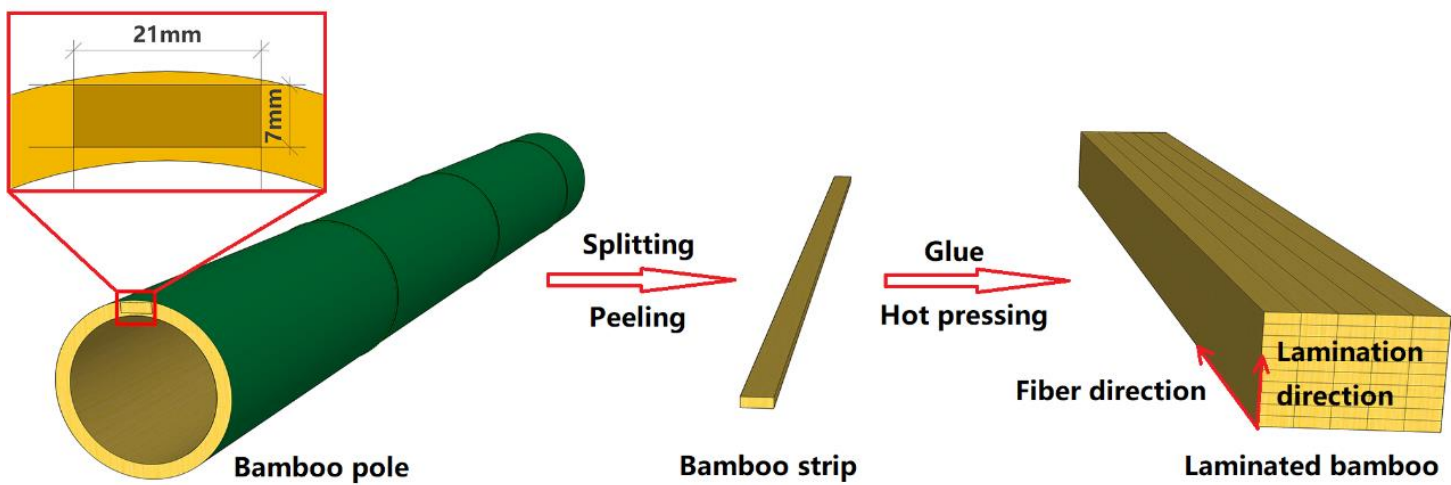

Fig.1 Main producing process

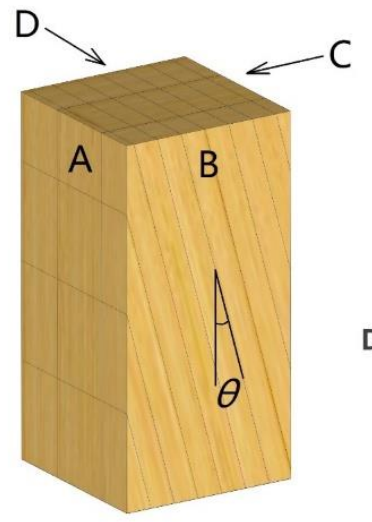

(a) Laminated bamboo sample

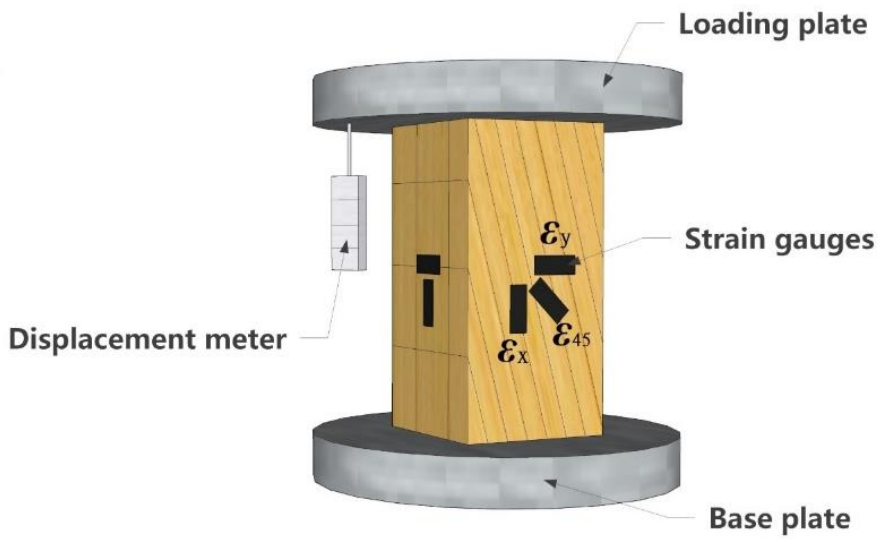

(b) Test scheme

Fig.2 Test design 


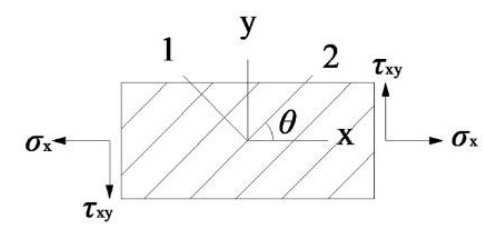

Fig.3 Different coordinates

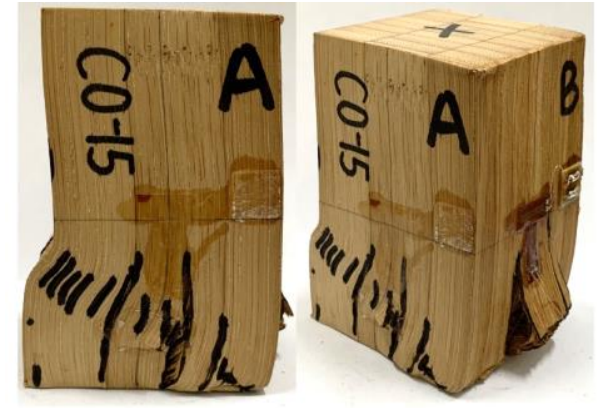

(a) Failure type I

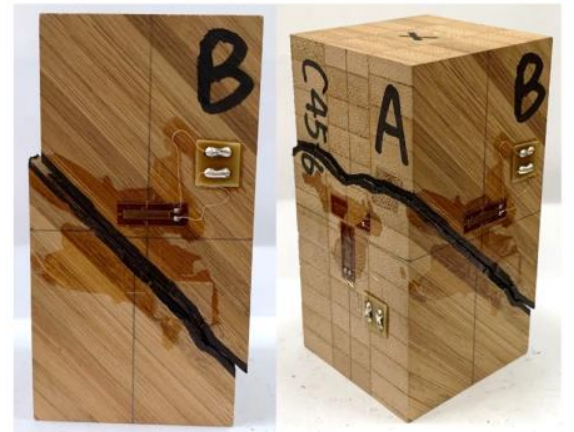

(c) Failure type III

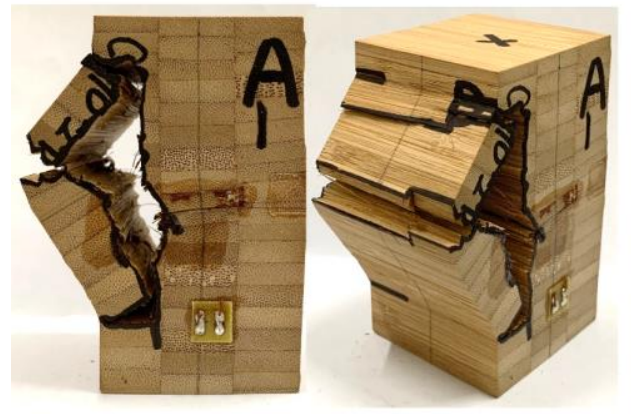

(e) Failure type V

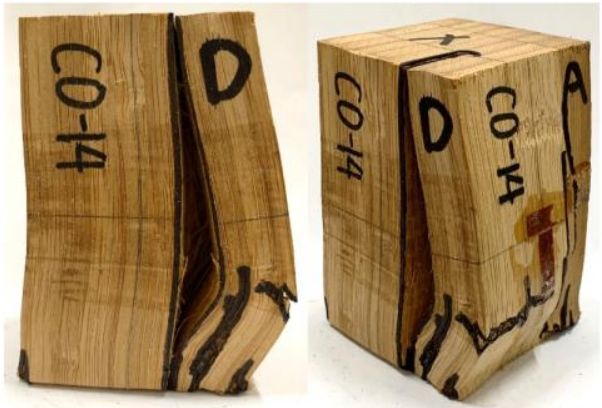

(b) Failure type II

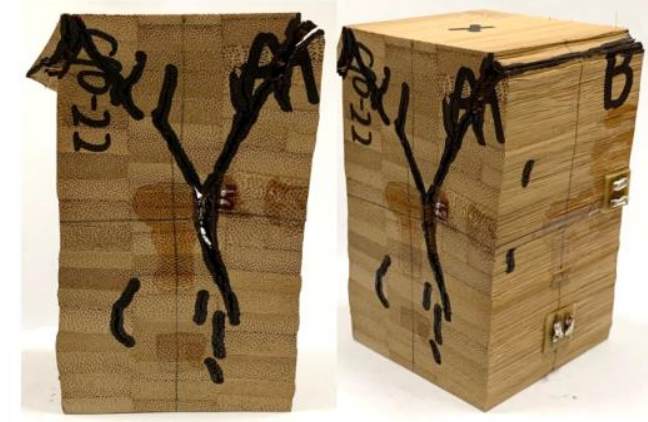

(d) Failure type IV

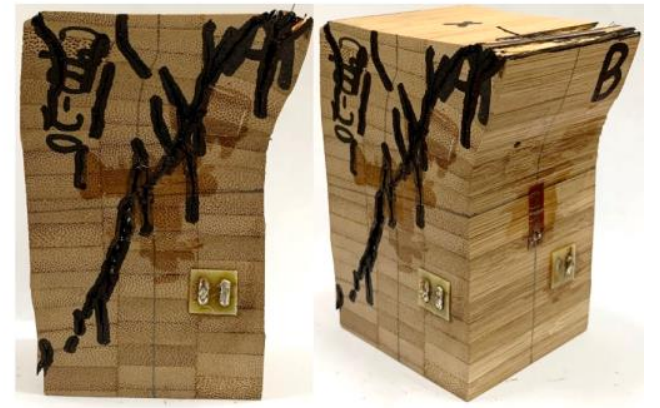

(f) Failure type VI

Fig.4 Failure types 


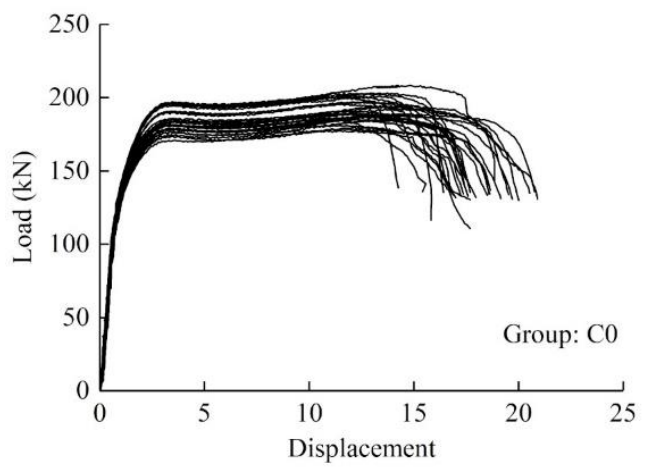

(a) $\mathrm{C} 0$

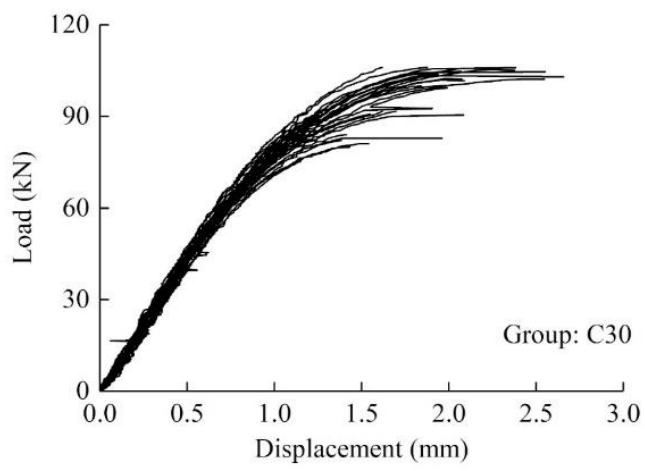

(c) $\mathrm{C} 30$

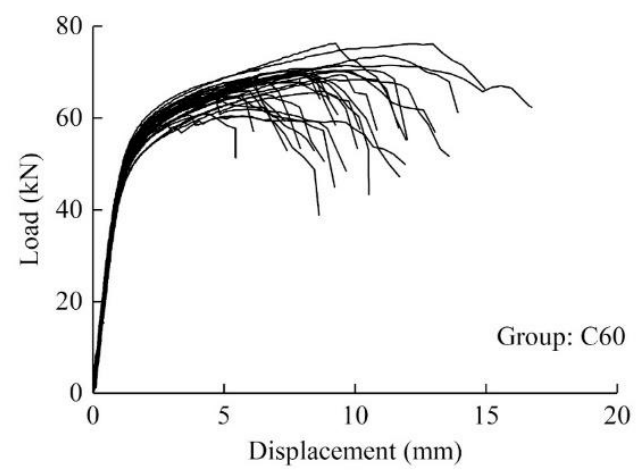

(e) $\mathrm{C} 60$

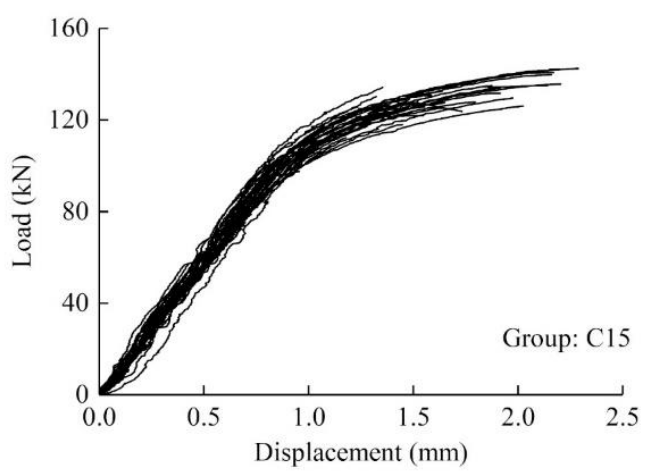

(b) $\mathrm{C} 15$

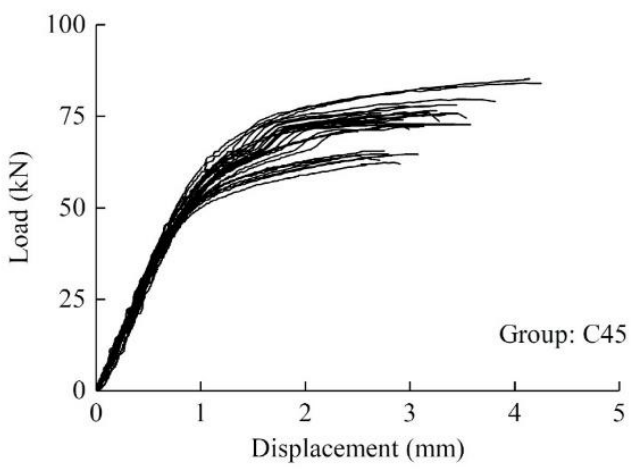

(d) $\mathrm{C} 45$

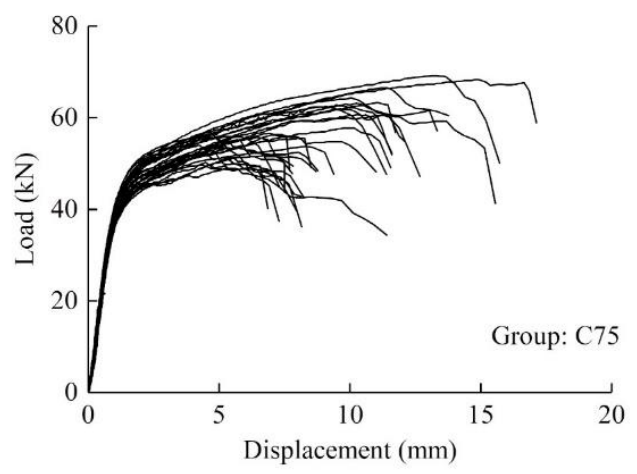

(f) $\mathrm{C} 75$

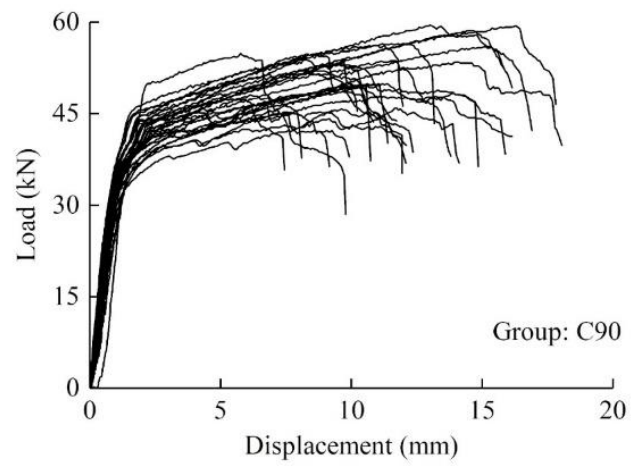

(g) $\mathrm{C} 90$

Fig.5 Load-displacement curves 


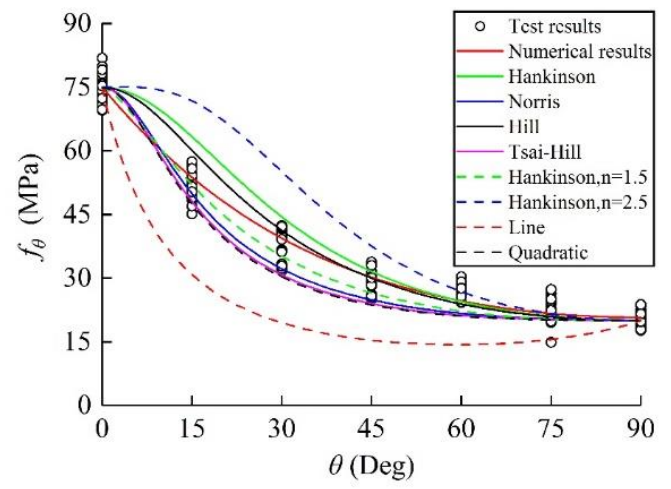

Fig.6 Prediction of compression strength

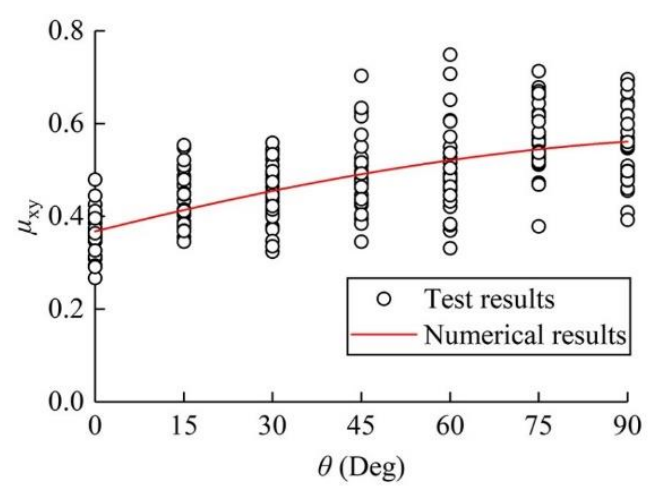

(a) $\mathrm{A} / \mathrm{C}$ plane

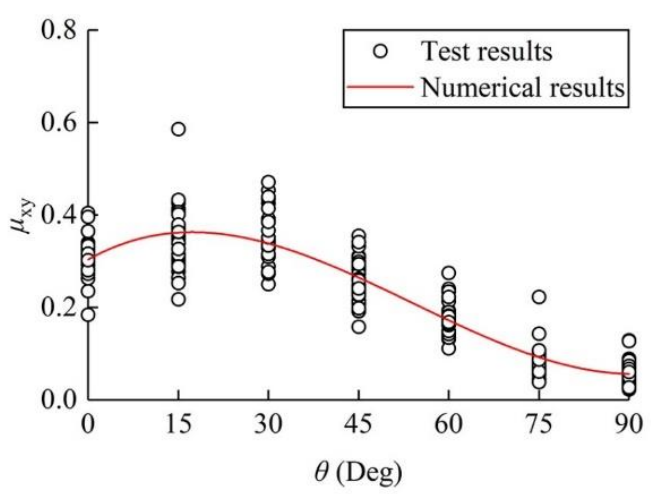

(b) $\mathrm{B} / \mathrm{D}$ plane

Fig.7 Poisson's ratio 


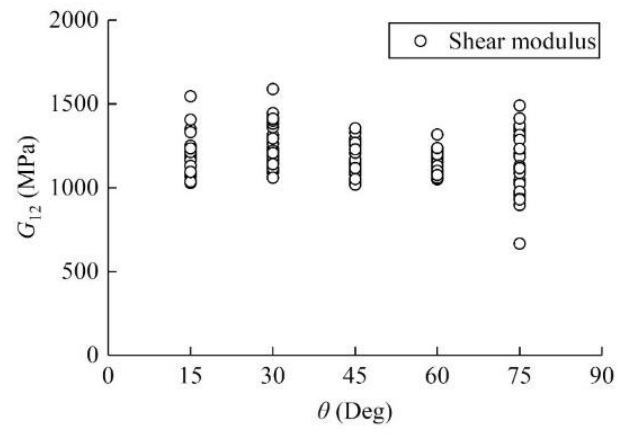

(a) Shear modulus

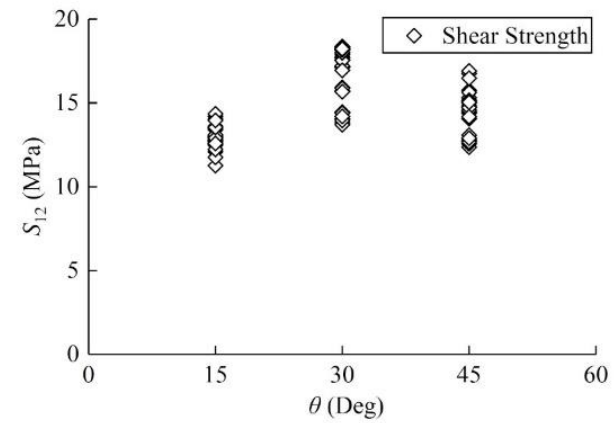

(b) Shear strength

Fig.8 Shear properties

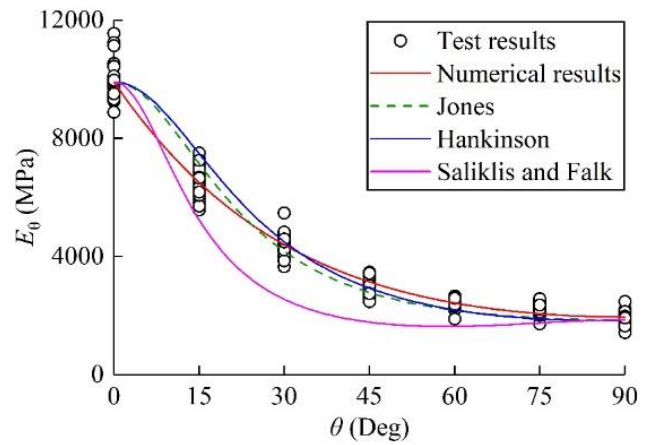

Fig.9 Prediction of elastic modulus 


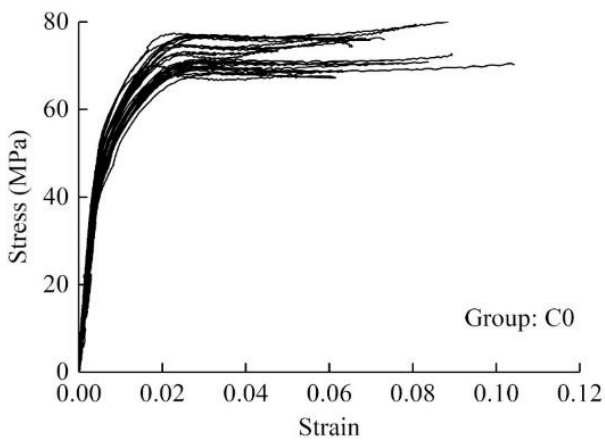

(a) $\mathrm{C} 0$

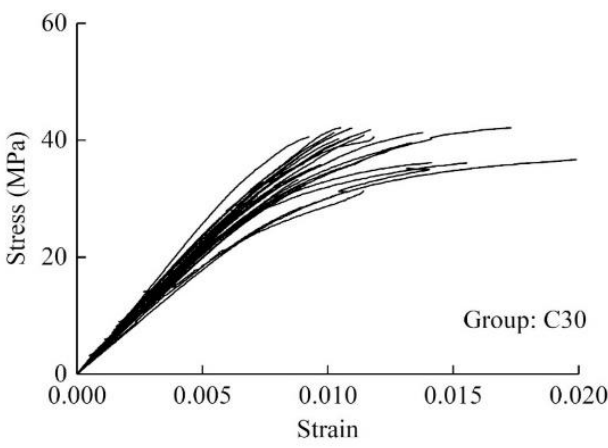

(c) $\mathrm{C} 30$

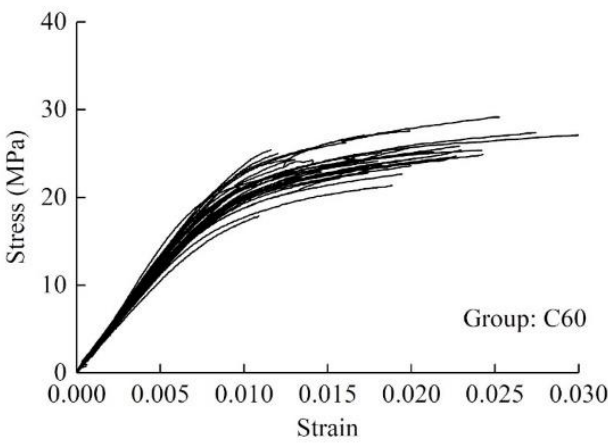

(e) $\mathrm{C} 60$

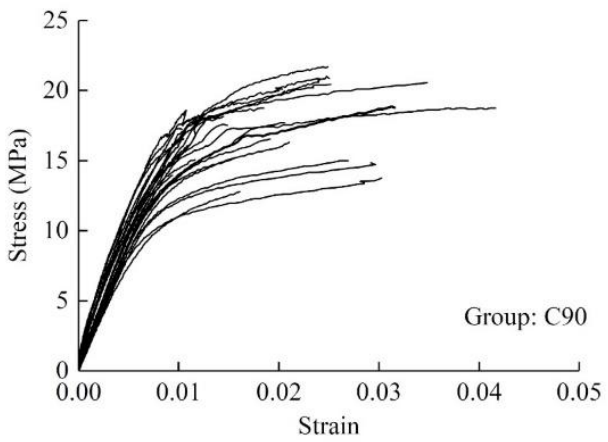

(g) $\mathrm{C} 90$

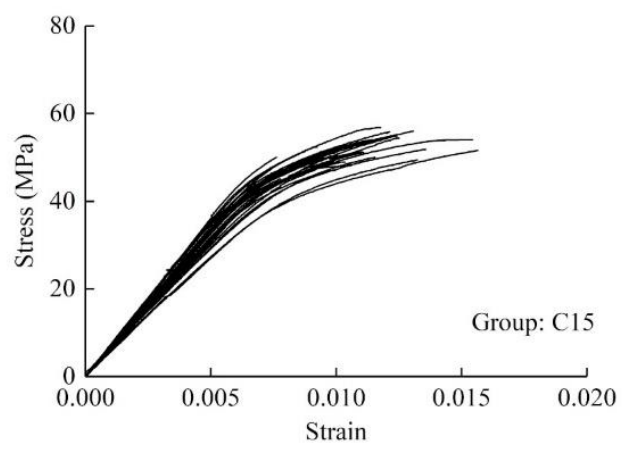

(b) $\mathrm{C} 15$

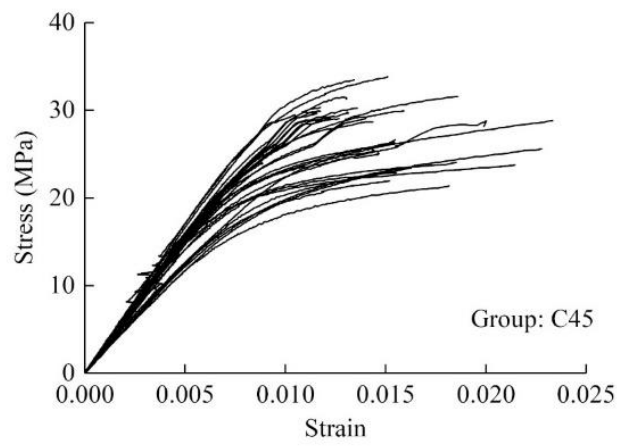

(d) $\mathrm{C} 45$

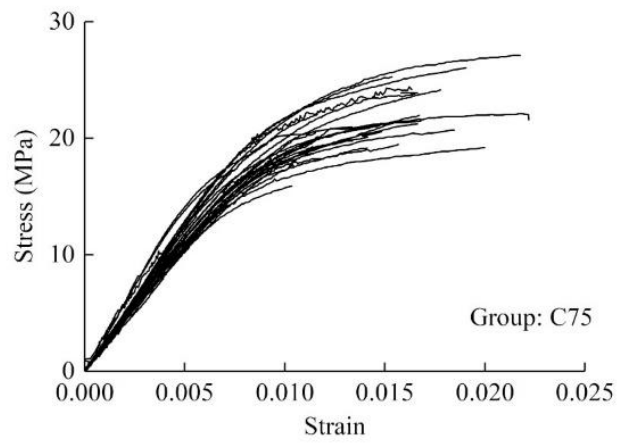

(f) $\mathrm{C} 75$

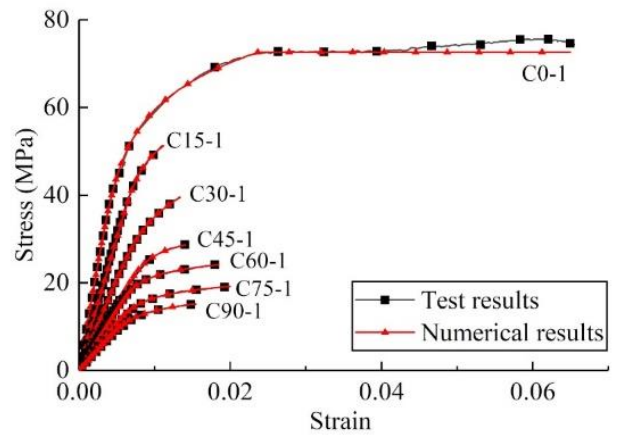

(h) Prediction of stress-strain curves

Fig.10 Stress-strain curves 


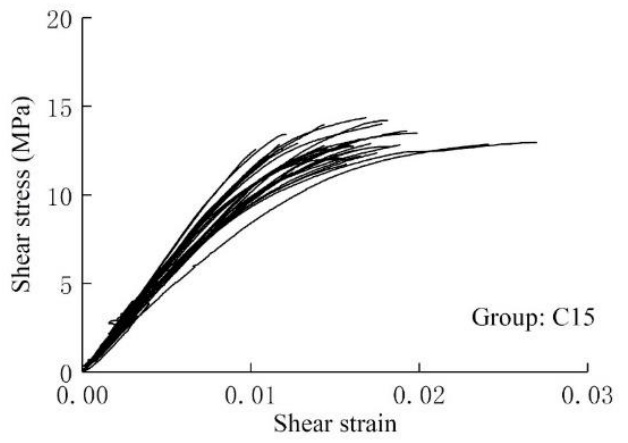

(a) $\mathrm{C} 15$

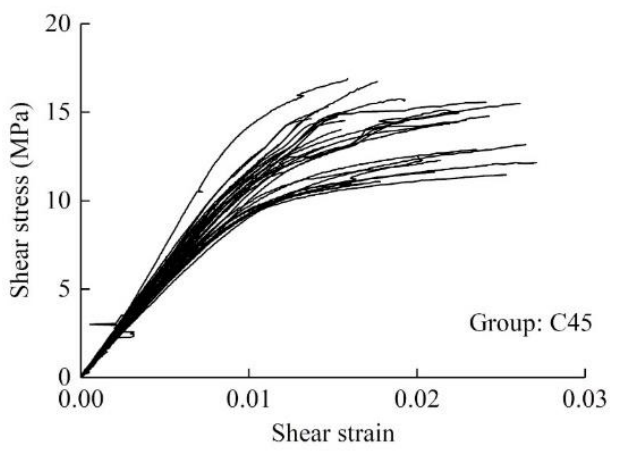

(c) $\mathrm{C} 45$

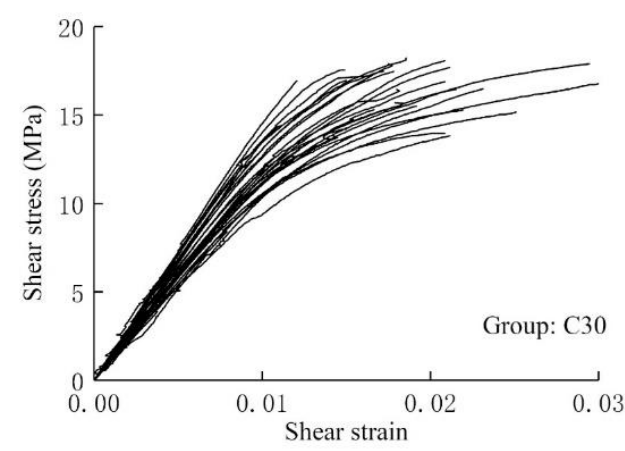

(b) $\mathrm{C} 30$

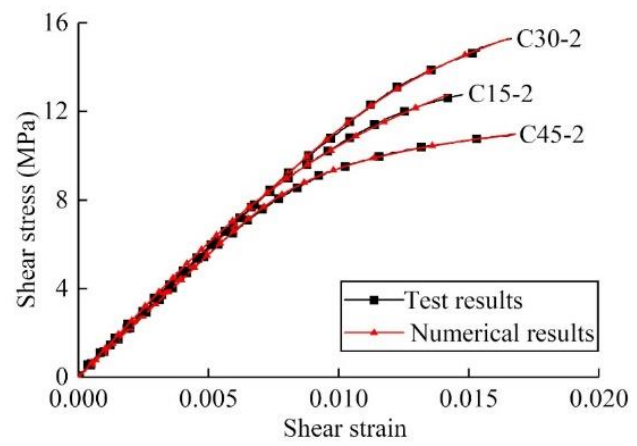

(d) Prediction of shear stress-strain curves

Fig.11 Shear stress-strain curves 
Table 1 Test results

\begin{tabular}{|c|c|c|c|c|c|c|c|c|}
\hline Group & & $\begin{array}{l}\text { Ultimate load } \\
\qquad / \mathrm{N}\end{array}$ & $\begin{array}{l}\text { Compression } \\
\text { strength /MPa }\end{array}$ & $\begin{array}{l}\text { Apparent elastic } \\
\text { modulus / } \mathrm{MPa}\end{array}$ & $\begin{array}{l}\text { Apparent shear } \\
\text { modulus } / \mathrm{MPa}\end{array}$ & $\begin{array}{c}\text { Shear strength } \\
\qquad / \mathrm{MPa}\end{array}$ & $\begin{array}{l}\text { Poisson's } \\
\text { ratio } \mathrm{A} / \mathrm{C}\end{array}$ & $\begin{array}{l}\text { Poisson's } \\
\text { ratio B/D }\end{array}$ \\
\hline \multirow{4}{*}{$\mathrm{C} 0$} & Mean & 191488 & 75.1 & 9913.5 & & & 0.36 & 0.31 \\
\hline & SDV & 7848.0 & 3.11 & 597.8 & & & 0.044 & 0.042 \\
\hline & $\mathrm{COV}$ & 0.0410 & 0.0414 & 0.0603 & & & 0.1231 & 0.1346 \\
\hline & $\mathrm{CHV}$ & 178382 & 69.9 & 8915.2 & & & & \\
\hline \multirow{4}{*}{$\mathrm{C} 15$} & Mean & 129483 & 51.8 & 6570.1 & 1166.0 & 13.0 & 0.43 & 0.34 \\
\hline & SDV & 6835.3 & 2.74 & 476.6 & 120.7 & 0.68 & 0.057 & 0.070 \\
\hline & $\mathrm{COV}$ & 0.0528 & 0.0529 & 0.0725 & 0.1036 & 0.0529 & 0.1331 & 0.2029 \\
\hline & $\mathrm{CHV}$ & 118068 & 47.2 & 5774.2 & 964.3 & 11.8 & & \\
\hline \multirow{4}{*}{$\mathrm{C} 30$} & Mean & 96331 & 38.4 & 4399.4 & 1239.7 & 16.6 & 0.45 & 0.36 \\
\hline & SDV & 9265.7 & 3.73 & 333.6 & 130.4 & 1.61 & 0.077 & 0.055 \\
\hline & $\mathrm{COV}$ & 0.0962 & 0.0973 & 0.0758 & 0.1052 & 0.0969 & 0.1561 & 0.1557 \\
\hline & $\mathrm{CHV}$ & 80857 & 32.1 & 3842.2 & 1021.9 & 13.9 & & \\
\hline \multirow{4}{*}{$\mathrm{C} 45$} & Mean & 73045 & 29.0 & 3001.0 & 1162.7 & 14.5 & 0.049 & 0.26 \\
\hline & SDV & 6319.9 & 2.47 & 255.0 & 89.7 & 1.24 & 0.077 & 0.048 \\
\hline & $\mathrm{COV}$ & 0.0865 & 0.0849 & 0.0850 & 0.0772 & 0.0857 & 0.1561 & 0.1866 \\
\hline & $\mathrm{CHV}$ & 62491 & 24.9 & 2575.2 & 1012.9 & 12.4 & & \\
\hline \multirow{4}{*}{$\mathrm{C} 60$} & Mean & 68267 & 27.2 & 2426.2 & 1142.4 & & 0.50 & 0.18 \\
\hline & SDV & 3936.6 & 1.54 & 172.3 & 70.6 & & 0.094 & 0.034 \\
\hline & $\mathrm{COV}$ & 0.0577 & 0.0566 & 0.0710 & 0.0618 & & 0.1878 & 0.1912 \\
\hline & $\mathrm{CHV}$ & 61692 & 24.6 & 2138.5 & 1024.5 & & & \\
\hline \multirow{4}{*}{$\mathrm{C} 75$} & Mean & 57093 & 22.7 & 2268.4 & 1111.2 & & 0.57 & 0.08 \\
\hline & SDV & 6536.6 & 2.56 & 181.5 & 189.5 & & 0.070 & 0.033 \\
\hline & $\mathrm{COV}$ & 0.1145 & 0.1127 & 0.0800 & 0.1706 & & 0.1226 & 0.3933 \\
\hline & $\mathrm{CHV}$ & 46177 & 18.4 & 1965.4 & 794.7 & & & \\
\hline \multirow{4}{*}{$\mathrm{C} 90$} & Mean & 51141 & 20.5 & 1853.9 & & & 0.55 & 0.06 \\
\hline & SDV & 4471.1 & 1.79 & 217.3 & & & 0.079 & 0.027 \\
\hline & $\mathrm{COV}$ & 0.0874 & 0.0872 & 0.1172 & & & 0.1428 & 0.4466 \\
\hline & $\mathrm{CHV}$ & 43675 & 17.5 & 1491.0 & & & & \\
\hline
\end{tabular}


Table 2 Comparison to wood and wood-based products

\begin{tabular}{ccccc}
\hline Materials & $\begin{array}{c}\text { Compression strength } \\
\text { parallel to grain } \\
\text { /MPa }\end{array}$ & $\begin{array}{c}\text { Elastic modulus } \\
\text { parallel to grain } \\
\text { /MPa }\end{array}$ & $\begin{array}{c}\text { Compression strength } \\
\text { perpendicular to grain } \\
\text { /MPa }\end{array}$ & $\begin{array}{c}\text { Elastic modulus } \\
\text { perpendicular to } \\
\text { grain } / \mathrm{MPa}\end{array}$ \\
\hline Laminated bamboo & 75.1 & 9913.5 & 20.5 & 1853.9 \\
Glue laminated spruce & 32 & 8600 & - & - \\
[28] & & & - & - \\
Thermally modified & 48.7 & - & -1250 \\
beech [29] & 38.3 & 13070 & 5.3 & 392 \\
Larch glulam [30] & - & - & 4.93 & - \\
CLT-SPF lumber [31] & 50.3 & 11900 & 7 & - \\
Beech, American [32] & 38.3 & 10900 & 3.4 & - \\
Yellow poplar [32] & 39.3 & 8500 & 5 & 870 \\
Spruce [32] & - & 12830 & - & \\
Douglas fir [33] & & & & \\
\hline
\end{tabular}

